\title{
Neuro-Fuzzy Approach on Core Resistance Estimation at Loss Minimization Control of Permanent Magnet Synchronous Motor
}

\author{
Huseyin Erdogan ${ }^{1}$, Mehmet Ozdemir ${ }^{2}$ \\ ${ }^{1}$ Department of Electronics Engineering, Dicle University, \\ Dicle University, 21280 Diyarbakir, Turkey \\ ${ }^{2}$ Department of Electronics Engineering, Firat University, \\ Firat University, 23119 Elazig, Turkey \\ erdogan@dicle.edu.tr
}

\begin{abstract}
Iron losses are among the most significant losses occurring on the Permanent Magnet Synchronous Motor (PMSM). These losses consume active power and cause heat in the iron core. Due to this behavior, they can be represented by an equivalent resistance to make the computations simple. Determining the equivalent core resistance is also a major problem. Computing these lost power is very difficult especially in dynamic applications because these lost power varies by partial differential equations.

This study aims to estimate the dynamic core resistance depended on inconstant operating conditions online, and compare the performance of the motor with dynamic versus fixed core resistance at the designed loss minimization algorithm. In order to obtain this estimation, firstly the finite element calculations have been made for many different operating speeds and lost power values were gathered for each speed. Then corresponding core resistance for each power value has been calculated with the dynamic model of a PMSM. Finally, a Neuro-Fuzzy estimator has been designed by computations on the gathered resistance values to estimate the core resistance for different operating conditions. At the end the obtained results are discussed with respect to feasibility of the system.
\end{abstract}

Index Terms-Energy efficiency; loss minimization control; neuro-fuzzy systems; permanent magnet synchronous motors.

\section{INTRODUCTION}

While working with systems using limited energy sources such as electric cars, lost power is clearly a crucial parameter to consider. It is a necessity to eliminate the losses as much as possible. This will prevent the car's limited power sources from being drained. During literature review, it was observed that many studies have been made on investigating the electrical losses in PMSMs. In their studies, [1] and [2] only investigated the copper losses. Neglecting other losses, such as core losses, results in an incomplete output. To achieve complete estimation of losses on PMSMs, some authors considered iron losses as well as copper losses. Authors of [3]-[8] investigated analyses on iron losses and/or the equivalent core loss resistance for fixed rotor speed operation conditions. In fixed speed, operation frequency remains fixed as well. This brings some

Manuscript received 2 September, 2015; accepted 30 January, 2016. ease especially, on loss calculations with frequency dependent partial differential equation components. However, it is apparent that such types of analyses have limited usage, so they cannot be used in variable speed operations. There are also some studies in which speed variance has been taken into account. Namely in [9]-[16], authors researched different particular speed values but revealed the results of their studies with a constant core resistance. In those cases, they neglected the variation of the core resistance related to frequency. As a matter of fact, that approach makes calculations easier, but again causes some errors by neglecting frequency effects. On the other hand, authors of [17]-[20] have examined core resistance changes in variable speeds. These authors, like mentioned before, carried out the analyses on particular speed values only. So they neglected speed variation between the selected speed values. Finally, the authors of [21]-[24] have investigated dynamic changes on the core resistance with variable speeds by using very complex analytical calculations. So after reviewing the literature, the need of an intelligent estimator became clear to determine core resistance dynamically according to varying speeds. In this context, this study demonstrates a neuro-fuzzy core resistance estimator for an interior permanent magnet synchronous motor; and it discusses the results in comparison with operating conditions which have fixed core resistance.

\section{Finite Element AnAlysis of CORE LOSSES IN PMSM}

In loss minimization studies of PMSMs, the primary problem is to identify a motor's iron loss which has great importance in the loss minimization process. Analytical methods to solve this problem seem quite complicated because representations of losses include partial differential equations [5]-[7], [19]-[26]. In this context, by investigating the papers numbered [4], [7], [8], [13], [17], [20], [22], [27], the use of a motor based on the Finite Elements Method (FEM) modelling has been chosen as the most suitable solution for this problem.

FEM is a method used in the solution of Laplace and Poisson-type partial differential equations. Using FEM, fluxes in a motor, torque produced by the motor and iron loss of the motor can be calculated in detail based on the 
physical size of the motor, and various parameters of the materials used.

In this study, a FEM analysis was carried out from a pre made educational demonstration of a finite element model which was created and released by Cedrat, embedded in Flux 2D software. (For more information about the FEM model please visit the Cedrat webpage. The analyses were carried out under a registered trial license.

Consequently, hysteresis loss power $\left(W_{h}\right.$ [Watt] $)$ and eddy loss power ( $W_{e}[$ Watt]), which were defined in (1) and (2) respectively [6], as two main components of total iron loss power $\left(W_{f e}[\right.$ Watt] $)$ were found by means of running FEM analysis for different constant speed rates and the obtained results are shown in Fig. 1

$$
W_{h}=k_{h}[1+c(r-1)] B^{2} f,
$$

where $B[\mathrm{~Wb}]$ is the peak value of the magnetic flux density, $k_{h}$ is the material constant, $c$ is the magnetic flux density ratio $\left(B_{\min } / B_{\max }\right), r$ is the empirical factor and $f[\mathrm{~Hz}]$ is the fundamental frequency

$$
W_{e}=k_{e c} \sum_{n=1}^{\infty} B_{n}^{2}(n f)^{2} .
$$

$B_{n}[\mathrm{~Wb}]$ is the peak value of the magnetic flux density for the harmonic order $n$. Herein if the skin effect of the eddy current is neglected, $k_{e c}$ can be written as

$$
k_{e c}=\frac{\pi^{2} d^{2}}{6 \rho_{e} \rho},
$$

where $d$ is the sheet thickness, $\rho$ is the sheet density and $\rho_{e}$ is the specific electrical resistance of the steel.

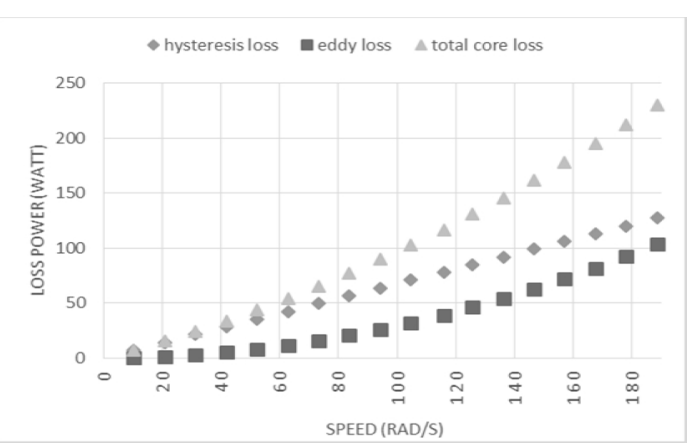

Fig. 1. Core losses on PMSM.

From Fig. 1, it can be seen clearly that the change in the eddy losses has a quadratic shape which responds to change of frequency as defined in (1). And the change in the hysteresis loss has a linear shape which suits the definition given in (2).

It is possible to calculate iron core resistance $R_{c}[\Omega]$ in terms of the total iron loss power obtained in Fig. 1. In this study, the preformed lossless model was operated at each values of speed given in Fig. 1 , using $I_{d}=0$ control method. Than the $\mathrm{u}_{0}$ voltage values obtained from these operations were used with $W_{f e}[\mathrm{~W}]$ values obtained from FEM analyses used in (5) which can be derived from $\mathrm{d}$ and $\mathrm{q}$ axis equivalent circuits given in Fig. 2 and Fig. 3 consequently [14]. $R_{c}[\Omega]$ resistance was found for each speed point as shown in Fig. 4. The other parameters of the PMSM are given in Table I.

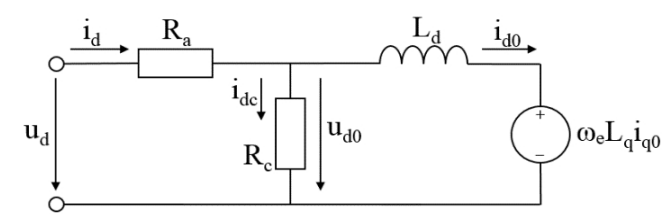

Fig. 2. d-axes equivalent circuit of a PMSM with core resistance.

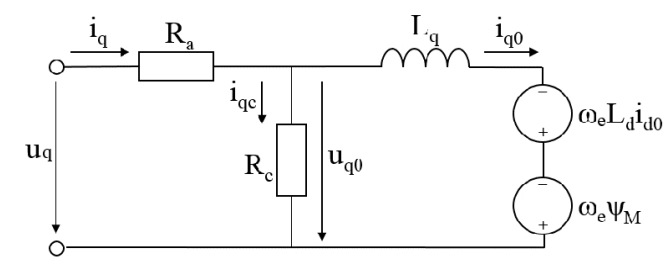

Fig. 3. q-axes equivalent circuit of a PMSM with core resistance.

TABLE I. PMSM PARAMETERS

\begin{tabular}{|c|c|}
\hline Parameter (unit) & Value \\
\hline $\mathrm{p}_{\mathrm{p}}(-)$ & 4 \\
\hline $\mathrm{R}_{\mathrm{a}}(\Omega)$ & 0.42 \\
\hline$\Psi_{\mathrm{M}}(\mathrm{Wb})$ & 0.5052 \\
\hline $\mathrm{J}\left(\mathrm{kgm}^{2}\right)$ & 0.0637 \\
\hline $\mathrm{L}_{\mathrm{d}}(\mathrm{mH})$ & $2.11 \mathrm{e}-3$ \\
\hline $\mathrm{L}_{\mathrm{q}}(\mathrm{mH})$ & $8.98 \mathrm{e}-3$ \\
\hline Number of stator slots $(-)$ & 48 \\
\hline Number of phases (-) & 3 \\
\hline Connection type (-) & wye \\
\hline Magnet type (-) & NdFeB \\
\hline Lamination type (-) & M270-35A \\
\hline Outer diameter (mm) & 242 \\
\hline Stack length $(\mathrm{mm})$ & 75 \\
\hline
\end{tabular}

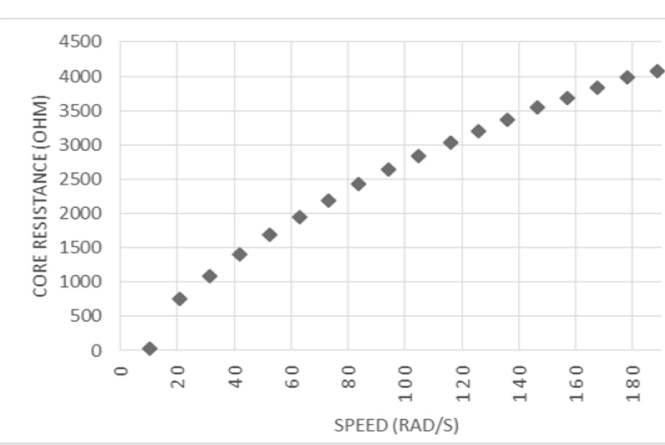

Fig. 4. Core resistance variation vs speed.

For the resistors shown in the circuit, $R_{c}[\Omega]$ stands for iron core resistance and $R_{a}[\Omega]$ represents phase resistance. Currents $i_{d}, i_{q}, i_{d c}, i_{q c}, i_{d 0}$ and $i_{q 0}[\mathrm{~A}]$ represent stator, $\mathrm{d}$ and $\mathrm{q}$ are axis currents which pass over the iron core resistance and in parallel to iron core resistance respectively. In addition, $u_{d}$ and $u_{q}[\mathrm{~V}]$ stand for $\mathrm{d}$ and $\mathrm{q}$ axis voltages respectively; $L_{d}$ and $L_{q}[\mathrm{H}]$ are $\mathrm{d}$ and $\mathrm{q}$ axes inductance, and $\psi_{M}[\mathrm{~Wb}]$ represents flux density of the permanent magnets:

$$
\begin{gathered}
u_{0}^{2}=u_{d 0}^{2}+u_{q 0}^{2}, \\
W_{f e}=W_{h}+W_{e}=\frac{\omega_{e}^{2}\left(\rho L_{q q 0}\right)^{2}}{R_{c}}+\frac{\omega_{e}^{2}\left(L_{d} i_{d 0}+\psi_{M}\right)^{2}}{R_{c}}=\frac{u_{0}^{2}}{R_{c}} .
\end{gathered}
$$

\section{CORE RESISTANCE ESTIMATION WITH ANFIS}

In order to analyze loss in variable speed drive systems, 
core resistance values of all corresponding speed values must be known. The finite element method cannot be used in dynamic analysis because FEM models require working with constant values. To perform a dynamic loss control, the core resistance values corresponding to all speeds must be known. The core resistance information can be gathered by a function which was defined based on values given in Fig. 4. The function can be defined with classical probability and statistics calculations as well as complicated mathematical calculations. In this regard, intelligent systems are emerging as the most appropriate solution for dynamically determining the core resistance.

The most popular emerging intelligent systems in the literature are based on fuzzy logic. A fuzzy system is a system based on fuzzy logic, in which the idea is to infer information about a variable from the information about its relation with another variable and finally reach information about the last one.

There are three main parts in a fuzzy system. First one is the fuzzification interface which translates the observed input into a fuzzy proposition (fuzzy input). Second one is the fuzzy inference machine that applies fuzzy logic and obtains a fuzzy output. And the last one, the defuzzification interface which translates the fuzzy output into the numerical output of the system [28].

A fuzzy system in process control uses rule bases for decision support. Setting up the rules seems to be an easy task if expert knowledge is available. However, there are three significant issues that complicate this procedure. Firstly, rules are not always true. Some rules fit in the majority of cases, but some exceptions do exist in some processes which cannot be described in detail here. Secondly, a rule with a set of inputs can fail to obtain a fuzzy output if a measurement involved in any input parameter is missing. And finally, some conditions are diagnosed by detecting patterns over time, so dynamics need to be considered [29]. To get rid of these complexities, a Neuro-Fuzzy system comes in handy.

The results obtained at Finite Element Method by constant speed simulations can be used as training data in case of creating a Neuro-Fuzzy intelligent prediction model.

In case of limited access to training data, results obtained by ANN may not be satisfactory. In this situation, a fuzzy logic controller can be used as an addition to improve the results obtained by the ANN controller [30].

As defined in detail in [31], [32], an Adaptive NeuroFuzzy Interference System (ANFIS) is a prediction system that can be used in a broad range of applications. In [32], Jang has indicated modeling of a nonlinear multivariable function, identification of nonlinear components in the control of dynamic systems, and identification of an irregular time series as possible types of applications.

In general terms, an ANFIS is an algorithm that automatically adjusts Sugeno type fuzzy logic membership functions with the aid of training data. The output of a Sugeno system may be linear functions or constants obtained by weight average defuzzification in the algorithm.

An ANFIS creates A Fuzzy Logic System (FLS) by using the input and output parameters. The parameters of the membership function are determined solely by a backpropagation learning algorithm or in the form of a hybrid learning algorithm combined with the method of a least squares algorithm.

While designing a neural-fuzzy controller for existing problems, rotor speed values were taken as input parameters and core resistance values corresponding to these speeds were taken as output parameters. Design was implemented with a Adaptive Neuro Fuzzy Interference System (ANFIS) toolbox in Matlab. Within this design triangle, TRIMF membership function type was used. The number of membership functions was chosen as three. The input membership functions were formed as shown in Fig. 5.

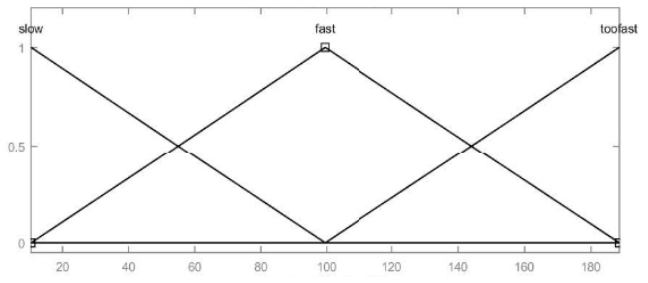

Fig. 5. Membership functions for core resistor estimator

The results obtained from the Neuro-fuzzy estimation system are shown in Fig. 6.

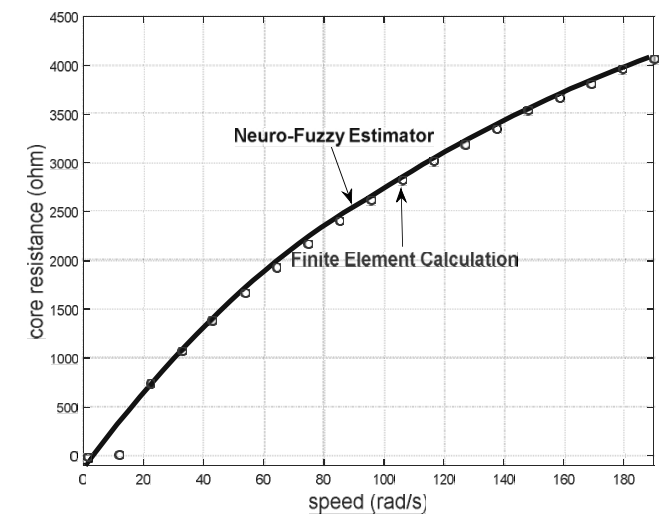

Fig. 6. Comparison estimated core resistance with finite element results.

As shown in Fig. 6, the neuro-fuzzy estimation system estimated the core resistance values with great accuracy. Thus, this system can clearly be used in variable speed operations with high accuracy.

\section{Minimum LOSS CONTROL With CONSTANT RESISTANCE VS. DYNAMIC RESISTANCE}

In this section, a comparison is made between dynamic and constant core resistance circumstances. During the first $0.2 \mathrm{~s}$, the motor operated at the $70 \mathrm{rad} / \mathrm{s}$ constant speed value which is below the nominal speed $(94.28 \mathrm{rad} / \mathrm{s})$ of the motor. Then in order to examine the effects of speed changes on the motor between $0.2 \mathrm{~s}-0.3 \mathrm{~s}$, the speed was increased in a linear fashion with a $550 \mathrm{rad} / \mathrm{s}^{2}$ slope value. Between $0.3 \mathrm{~s}$ and $0.45 \mathrm{~s}$, slop value was reduced to to $125 \mathrm{rad} / \mathrm{s}^{2}$. In addition to examining the motor's dynamic response to load changes, a dynamic load torque, whose value is defined as $\mathrm{T}_{\mathrm{y}}=3 \mathrm{w}_{\mathrm{m}}[\mathrm{Nm}]$, was used on the motor from the beginning of the operation.

In order to increase the efficiency of the motor, a MTPA \& FW controller was used on the motor. This controller created in our previous study given with the reference number [12], was created as a combination of the MTPA (Maximum Torque Per Ampere) and the FW (Field 
Weakening) control methods. The operation of this controller can be demonstrated with the flow diagram given in Fig. 7. In this diagram, $U_{s}$ and $U_{s m}[\mathrm{~V}]$ represent the inverter output voltage and the maximum phase voltage of the inverter respectively, where $\omega \mathrm{r}[\mathrm{rad} / \mathrm{s}]$ represents the measured rotor speed, $\omega_{r c}[\mathrm{rad} / \mathrm{s}]$ represents the critical angular frequency calculated by $U_{s m} / \psi_{m}$, and $\omega_{r A}[\mathrm{rad} / \mathrm{s}]$ represents the maximum speed at a positive constant torque limit.

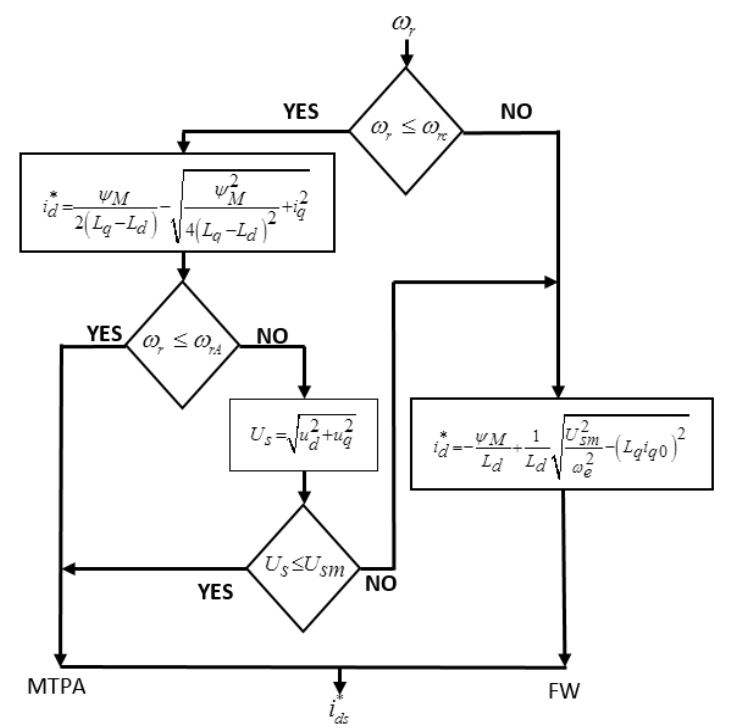

Fig. 7. Flow chart of MTPA\&FW controller.

The simulation was run twice, once with constant core resistance and once with dynamic core resistance, which came as an output from the designed Neuro-Fuzzy resistance estimator. $2637 \mathrm{ohm}$ taken as a constant resistance value obtained by finite element analysis, performed at the nominal operating speed of the motor. To be able to ensure that the loss minimization algorithm works, the results gathered from id $=0$ control, in which core losses have be neglected, were added to the figures.

Figure 8 shows the variation of $R_{c}$ obtained from the operation of the two cases.

As shown in Fig. 9, the rotor speed caught the reference speed curve with great success in both constant and variable resistance operating conditions.

Figure 10 shows the motor's load torque variation. In this figure it can be clearly seen that the load torque variations in both constant and variable $R_{c}$ operating conditions fit the desired ratio $\left(T_{y}=3 \omega_{\mathrm{m}}\right)$.

Motor's d axis current component variations are given in Fig. 11. Below nominal speed it can be clearly seen that the current has a greater value at variable $R_{c}$ control. However, in speeds higher than the nominal speed, the condition is the opposite. Also in the phase below the nominal speed, current ripples are reduced by the use of variable resistance.

The motor's iron core loss variations are shown in Fig. 12. These variations show that the control with constant $R_{c}$ results in less iron loss in slow speed operation phase. However, when the motor's speed exceeds the nominal speed and goes into high speed phase, the condition is the opposite. In addition, by the use of variable resistance, the ripple that occurs at starting point may be eliminated.

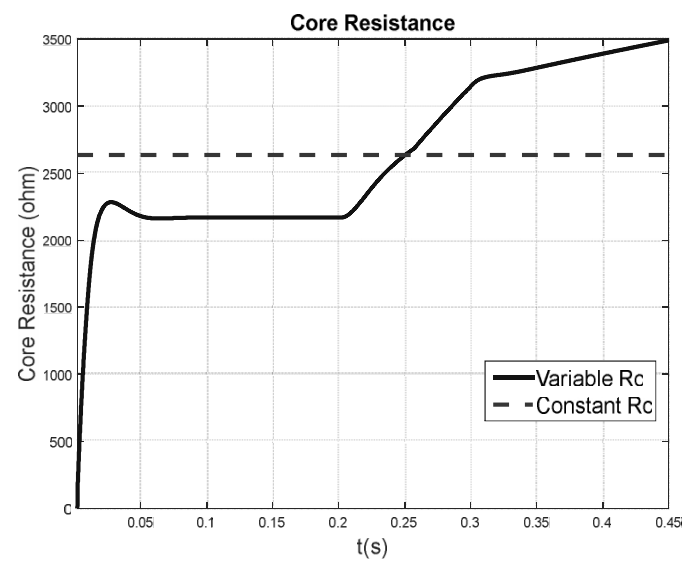

Fig. 8. Variation of Rc at operation scenario.

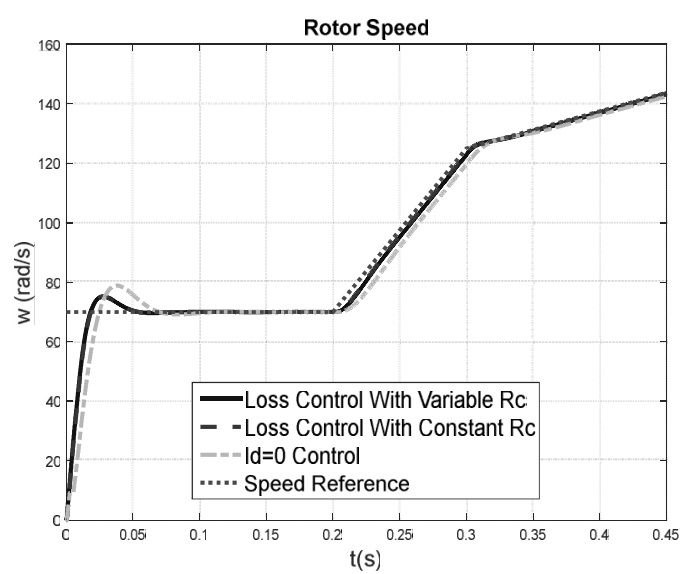

Fig. 9. Variation of rotor speed.

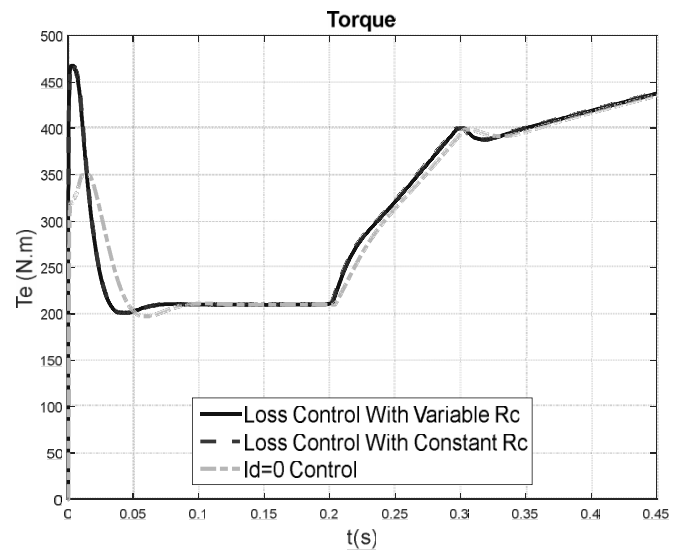

Fig. 10. Motor's load torque variation.
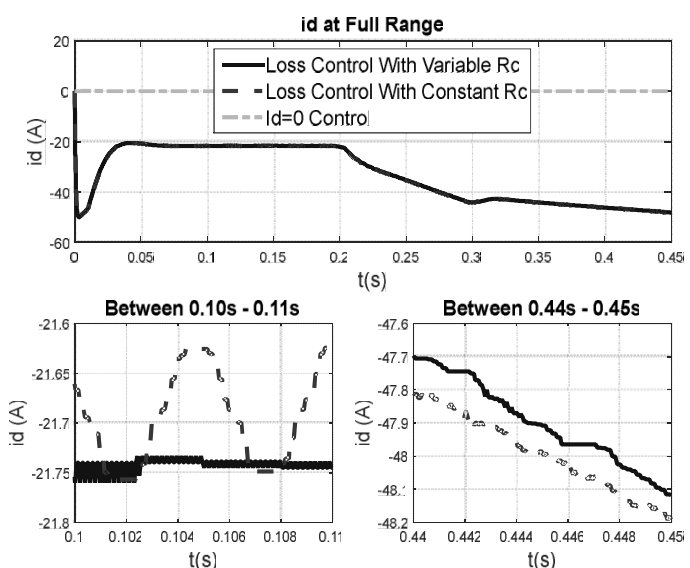

Fig. 11. $\mathrm{d}$ axis current component variations in full and selected time ranges. 


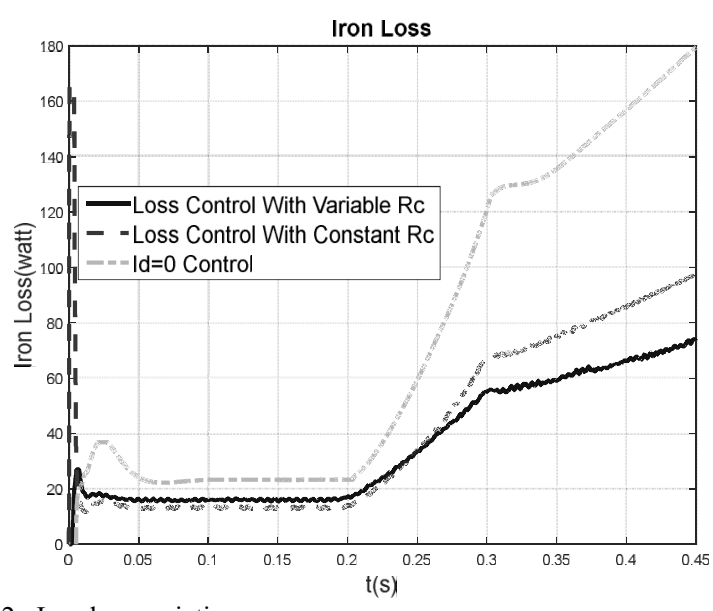

Fig. 12. Iron loss variations.

The motor's copper loss variations are shown in Fig. 13. Again, it can be seen that the variation differs in two speed phases. In low speed, phase control with constant resistor provides less power but contain more ripples.
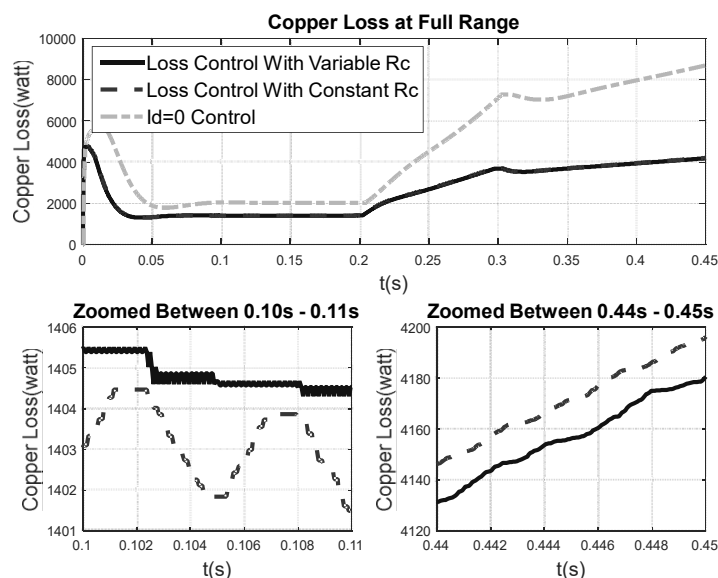

Fig. 13. Copper loss variations in full and selected time ranges.

The motor's total electrical losses, as sum of the iron and copper losses, are given in Fig. 14. Same behavior can be seen in copper loss variation.
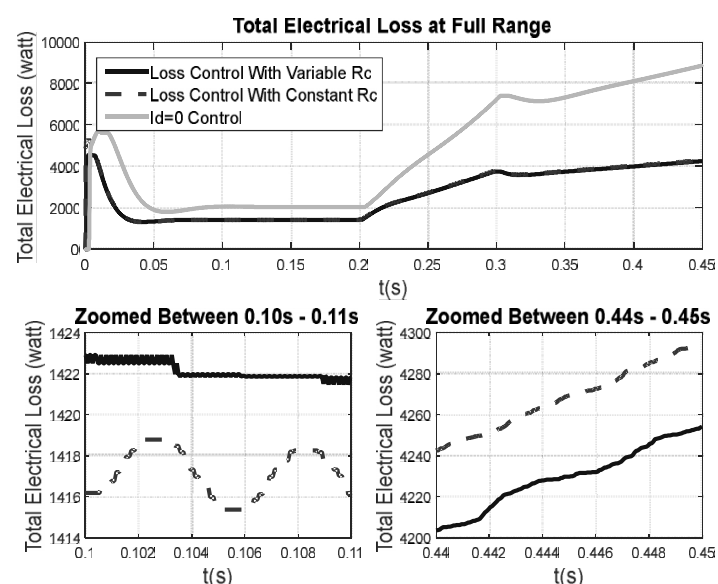

Fig. 14. Total electrical loss variations in full and selected time ranges.

Finally, the motor's efficiency variation was obtained as shown in Fig. 15. As shown below, the values in different regions also vary. In the low speed region, constant $R_{c}$ gives higher efficiency in contrast to the efficiency obtained in the high speed region.
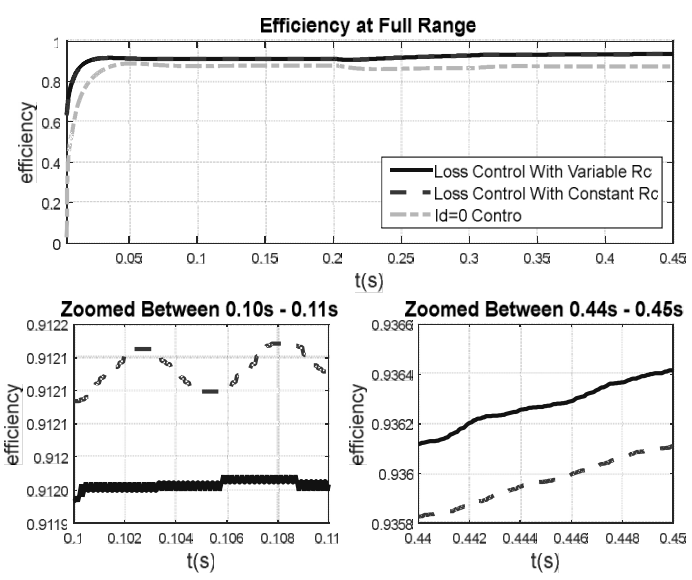

Fig. 15. Efficiency variations in full and selected time ranges.

\section{CONCLUSIONS}

In this study, an investigation is made to determine the variation effects of the core resistor on electrical losses of the permanent magnet synchronous motor. In this context, firstly a Neuro-Fuzzy based core resistor estimator was designed in order to eliminate a big deficiency found in the literature about determining dynamic core resistance. Then the obtained dynamic core resistance was used with a loss minimizing algorithm. Finally, the obtained results were compared with the results of the loss minimization application that used constant core resistance.

It is evident from the results that loss control can be applicable in cases of both constant and variable resistance. On one hand, using constant resistance provides great convenience in calculations. On the other hand, in practical applications with variable speed, it is not possible to keep core losses and consequently core resistance constant as a clearly demonstrated in (1) and (2). Therefore, it can be clearly seen from Fig. 11-Fig. 15 that taking the resistant constant in algorithms produces quite inaccurate results. Especially as seen in Fig. 12, applying a constant iron core resistance, while motor operates under nominal speed, provides a lower iron loss than usual and the results are reversed in the high speed region. In the case of applying estimated dynamic iron core resistance, more realistic results are obtained, so a more accurate analysis can be performed.

In applications such as electric vehicles, even the smallest power loss has great importance, therefore making the correct calculations an important requirement. This study makes it clear that this is only possible by taking into account the dynamic changes in iron core resistance. Making calculations using the dynamic resistance is a major requirement to perform more accurate loss minimization applications.

\section{REFERENCES}

[1] B. Asaei, B. Rahrovi, "Minimum-copper-loss control over full speed range of an IPMSM drive for hybrid electric vehicle application", in 2010 IEEE Vehicle Power and Propulsion Conf. (VPPC), Lille, 2010, pp. 1-6. [Online]. Available: http://dx.doi.org/10.1109/VPPC. 2010.5728999

[2] Y. S. Jeong, S. K. Sul, S. Hiti, K. M. Rahman, "Online minimumcopper-loss control of an interior permanent-magnet synchronous machine for automotive applications", IEEE Trans. Industry Applications, vol. 42, pp. 1222-1229, 2006. [Online]. Available: http://dx.doi.org/10.1109/TIA.2006.880910 
[3] Z. Wu, G. Li, Y. Zhu, "Efficient optimization control of permanent magnet synchronous motor using artificial neural network", International Journal On Advances in Information Sciences and Service Sciences, vol. 3, no. 7, pp. 260-267, 2011. [Online]. Available: http://dx.doi.org/10.4156/aiss.vol3.issue7.31

[4] G. Almandoz, G. Ugalde, J. Poza, A.J. Escalada, Matlab-Simulink Coupling to Finite Element Software for Design and Analysis of Electrical Machines, MATLAB - A Fundamental Tool for Scientific Computing and Engineering Applications. Katsikis, 2012, ch. 8. [Online]. Available: http://dx.doi.org/10.5772/46476

[5] H. Aorith, J. Wang, P. Lazari, "A new loss minimization algorithm for interior permanent magnet synchronous machine drives", in IEEE Int. Electric Machines \& Drives Conf. (IEMDC), Chicago, 2013, pp. 526-533. [Online]. Available: http://dx.doi.org/10.1109/IEMDC. 2013.6556146

[6] M. H. Gracia, E. Lange, K. Hameyer, "Numerical calculation of iron losses in electrical machines with a modified post-processing formula", in Proc. 16th Int. Symposium on Electromagnetic Fields COMPUMAG, Aachen, 2007, pp. 1-2. [Online]. Available: http://134.130.107.200/uploads/bibliotest/2007MHGModified.pdf

[7] S. H. Han, W. L. Soong, T. M. Jahns, "An analytical design approach for reducing stator iron losses in interior PM synchronous machines during flux-weakening operation", in IEEE Industry Applications Annual Meeting, New Orleans, 2007, pp. 103-110. [Online]. Available: http://dx.doi.org/ 10.1109/07IAS.2007.36

[8] G. Ugalde, G. Almandoz, J. Poza, A. Gonzalez, "Computation of iron losses in permanent magnet machines by multi-domain simulations", in 13th European Conf. Power Electronics and Applications, Barcelona, 2009. pp. 1-10. [Online]. Available: $\mathrm{http} / /$ ieeexplore.ieee.org/stamp/stamp.jsp?arnumber $=5279171$

[9] F. F. Bernal, A. Garefa-Cerrada, R. Faure, "Loss-minimization control of synchronous machines with constant excitation", in PESC Record - IEEE Annual Power Electronics Specialists Conf., Fukuoka, 1998, pp. 132-138. [Online]. Available: http://dx.doi.org/ 10.1109/PESC.1998.701890

[10] C. Cavallaro, A. O. Di Tommaso, R. Miceli, A. Raciti, G. R. Galluzzo, M. Trapanese, "Analysis a DSP implementation and experimental validation of a loss minimization algorithm applied to permanent magnet synchronous motor drives", in 29th Annual Conf. IEEE Industrial Electronics Society, (IECON 2003), 2003, pp. 312317. [Online]. Available: http://dx.doi.org/10.1109/IECON.2003. 1279998

[11] C. Cavallaro, A. O. Di Tommaso, R. Miceli, A. Raciti, G. R. Galluzzo, M. Trapanese, "Efficiency enhancement of permanentmagnet synchronous motor drives by online loss minimization approaches", IEEE Trans. Industrial Electronics, vol. 52, pp. 11531160,2005 . [Online]. Available: http://dx.doi.org/10.1109/ TIE.2005.851595

[12] H. Erdogan, B. Gumus, M. Ozdemir, "Surekli mıknatisli senkron motorun minimum kayip kontrolu - minimum loss control of permanent magnet synchronous motor", in Elektrik, Elektronik, Bilgisayar ve Biyomedikal Mühendisliği Sempozyumu ve Sergisi. Bursa, 2014. pp. 27-29. [Online]. Available: http://www.emo.org.tr/ekler/60d457fc468defb ek.pdf (in Turkish)

[13] S. Kuttler, K. E. K. Benkara, G. Friedrich, F. Vangraefschepe, A. Abdelli, "Impact of the flux weakening on the iron losses in an internal permanent magnet synchronous machine", in Energy Conversion Congress and Exposition, Pittsburgh, 2014, pp. 41884195. [Online]. Available: http://dx.doi.org/10.1109/ECCE.2014. 6953971

[14] S. Morimoto, Y. Tong, Y. Takeda, T. Hirasa, "Loss minimization control of permanent magnet synchronous motor drives", IEEE Trans. Industrial Electronics, vol. 41, pp. 511-7, 1994. [Online]. Available: http://dx.doi.org/10.1109/41.315269

[15] M. N. Uddin, S. Member, H. Zou, F. Azevedo, "Online loss minimization based adaptive flux observer for direct torque and flux control of PMSM drive", in IEEE Industry Applications Society Annual Meeting, Vancouver, 2014, pp. 1-7. [Online]. Available: http://dx.doi.org/10.1109/IAS.2014.6978395

[16] Y. Watanabe, T. W. Kim, A. Mushi, A. Kawamura, "Research on overall efficiency improvement of electric vehicles by MTHDPAM control method", in 15th Int. Power Electronics and Motion Control Conf. (EPE/PEMC), Novi Sad, 2012. [Online]. Available: http://dx.doi.org/10.1109/EPEPEMC.2012.6397477
[17] A. Krings, S. Nategh, O. Wallmark, J. Soulard, "Local iron loss identification by thermal measurements on an outer-rotor permanent magnet synchronous machine", in 2012 15th Int. Conf. Electrical Machines and Systems, Sapporo, 2012, pp. 1-5. [Online]. Available: http://ieeexplore.ieee.org/stamp/stamp.jsp?tp=\&arnumber $=6401970$

[18] R. Dutta, L. Chong, F. M. Rahman, "Analysis and experimental verification of losses in a concentrated wound interior permanent magnet machine", Progress In Electromagnetics Research B, vol. 48, pp. 221-248, 2013. [Online]. Available: http://dx.doi.org/10.2528 PIERB12110715

[19] I. Shchur, A. Rusek, O. Makarchuk, M. Mandzyuk, "Definition of parameters of mathematical model of pmsm for electric vehicles on the basis of computer and experimental research", Maszyny Elektryczne: zeszyty problemowe, vol. 1, no. 101, pp. 147-152, 2014. [Online]. Available: http://www.komel.katowice.pl/ZRODLA/ FULL/101/ref 28.pdf

[20] J. Soulard, "Modeling of iron losses in permanent magnet synchronous motors with field-weakening capability for electric vehicles", International Journal of Automotive Technology, vol. 4 pp. 87-94, 2003. [Online]. Available: http://urn.kb.se/resolve?urn= urn\%3Anbn\%3Ase\%3Akth\%3Adiva-22744

[21] J. Y. Lee, S. H. Lee, G. H. Lee, J. P. Hong, J. Hur, "Determination of parameters considering magnetic nonlinearity in an interior permanent magnet synchronous motor", IEEE Trans. Magnetics, vol. 42, pp. 1303-1306, 2006. [Online]. Available: http://dx.doi.org/10.1109/ TMAG.2006.871951

[22] B. H. Lee, S. O. Kwon, T. Sun, J. P. Hong, G. H. Lee, J. Hur, "Modeling of core loss resistance for $\mathrm{d}$-q equivalent circuit analysis of IPMSM considering harmonic linkage flux", IEEE Trans. Magnetics, vol. 47, pp. 1066-1069, 2011. [Online]. Available: http://dx.doi.org/ 10.1109/TMAG.2010.2099647

[23] S. Vaez, V. I. John, "Minimum loss operation of PM motor drives", in Proc. 1995 Canadian Conf. Electrical and Computer Engineering, Montreal, 1995, pp. 284-287. [Online]. Available: http://dx.doi.org/10.1109/CCECE.1995.528130

[24] A. H. Zarei, K. Abbaszadeh, K. Safari, "The analytical analysis of the rotor losses in the PMSM motors", in Proc. World Congress on Engineering and Computer Science. San Francisco, 2012. [Online]. Available:

http://www.iaeng.org/publication/WCECS2012/WCECS2012_pp104 4-1048.pdf

[25] I. Ducar, C. Marinescu, "The PMSM efficiency at variable speed for pumping applications", in Int. Conf. and Exposition on Electrical and Power Engineering, Iasi, 2014, pp. 912-916. [Online]. Available: http://dx.doi.org/10.1109/ICEPE.2014.6970044

[26] B. F. Fernandez, C. A. Garcia, R. Faure, "Determination of parameters in interior permanent magnet synchronous motors with iron losses without torque measurement", in Thirty-Fifth IAS Annual Meeting and World Conf. Industrial Applications of Electrical Energy, Rome, 2000, pp. 409-415. [Online]. Available: http://dx.doi.org/10.1109/IAS.2000.881143

[27] T. Finken, K. Hameyer, "Computation of iron and eddy-current losses in IPM motors depending on the field weakening angle and curren waveform", in XIV Int. Symposium on Electromagnetic Fields in Mechatronics, Electrical and Electronic Engineering, Arras, 2009, pp. 123-128. [Online]. Available: http://134.130.107.200/uploads/ bibliotest/2009TFIpm.pdf

[28] J. L. Castro, M. Delgado, "Fuzzy systems with defuzzification are universal approximators", IEEE Trans. Systems, vol. 26, pp. 149-152, 1996. [Online]. Available: http://dx.doi.org/10.1109/3477.484447

[29] A. Sala, T. M. Guerra, R. Babuska, "Perspectives of fuzzy systems and control", Fuzzy Sets and Systems, vol. 156, pp. 432-444, 2005. [Online]. Available: http://dx.doi.org/10.1016/j.fss.2005.05.041

[30] J. S. R. Jang, C. T. Sun, E. Mizutani, "Neuro-fuzzy and soft computing-a computational approach to learning and machine intelligence [Book Review]", in IEEE Trans. Automatic Control, vol 42, no. 10, pp. 1482-1484, 1997. [Online]. Available: http://dx.doi.org/10.1109/TAC.1997.633847J.S.R

[31] M. Valcic, R. Antonic, V. Tomas, "ANFIS based model for ship speed prediction", Brodogradnja, vol. 62, pp. 373-382, 2011. [Online]. Available: http://hrcak.srce.hr/75675

[32] J. S. R. Jang, "ANFIS: adaptive-network-based fuzzy inference system”, IEEE Trans. Systems, vol. 23, pp. 665-685, 1993. [Online]. Available: http://dx.doi.org/10.1109/21.256541 